OPEN ACCESS

Edited by:

Shuhai Xiao,

Virginia Tech, United States

Reviewed by:

Simon Darroch,

Vanderbilt University, United States

Marc Laflamme,

University of Toronto Mississauga,

Canada

*Correspondence:

Philip B. Vixseboxse

pbv22@cam.ac.uk

Specialty section:

This article was submitted to

Paleontology,

a section of the journal

Frontiers in Earth Science

Received: 22 August 2021 Accepted: 01 November 2021 Published: 07 December 2021

Citation:

Vixseboxse $P B$, Kenchington $C G$, Dunn FS and Mitchell EG (2021) Orientations of Mistaken Point Fronds Indicate Morphology Impacted Ability

to Survive Turbulence.

Front. Earth Sci. 9:762824. doi: 10.3389/feart.2021.762824

\section{Orientations of Mistaken Point Fronds Indicate Morphology Impacted Ability to Survive Turbulence}

\author{
Philip B. Vixseboxse ${ }^{1,2 *}$, Charlotte G. Kenchington ${ }^{2}$, Frances S. Dunn ${ }^{3}$ and Emily G. Mitchell ${ }^{4}$ \\ ${ }^{1}$ School of Earth Sciences, University of Bristol, Bristol, United Kingdom, ${ }^{2}$ Department of Earth Sciences, University of \\ Cambridge, Cambridge, United Kingdom, ${ }^{3}$ Oxford University Museum of Natural History, University of Oxford, Oxford, \\ United Kingdom, ${ }^{4}$ Department of Zoology, University of Cambridge, Cambridge, United Kingdom
}

The Ediacaran fossils of the Mistaken Point E surface have provided crucial insight into early animal communities, including how they reproduced, the importance of Ediacaran height and what the most important factors were to their community dynamics. Here, we use this iconic community to investigate how morphological variation between eight taxa affected their ability to withstand different flow conditions. For each of Beothukis, Bradgatia, Charniodiscus procerus, Charniodiscus spinosus, Plumeropriscum, Primocandelabrum, Thectardis and Fractofusus we measured the orientation and length of their stems (if present) and their fronds. We statistically tested each taxon's stem and frond orientation distributions to see whether they displayed a uniform or multimodal distribution. Where multimodal distributions were identified, the stem/frond length of each cohort was tested to identify if there were differences in size between different orientation groups. We find that Bradgatia and Thectardis show a bimodal felling direction, and infer that they were felled by the turbulent head of the felling flow. In contrast, the frondose rangeomorphs including Beothukis, Plumeropriscum, Primocandelabrum, and the arboreomorphs were felled in a single direction, indicating that they were upright in the water column, and were likely felled by the laminar tail of the felling flow. These differences in directionality suggests that an elongate habit, and particularly possession of a stem, lent greater resilience to frondose taxa against turbulent flows, suggesting that such taxa would have had improved survivability in conditions with higher background turbulence than taxa like Bradgatia and Thectardis, that lacked a stem and had a higher centre of mass, which may have fared better in quieter water conditions.

Keywords: Ediacaran, Mistaken Point, orientations, turbidite, rangeomorphs, arboreomorphs

\section{INTRODUCTION}

The Ediacaran macrobiota is a polyphyletic assemblage of organisms (Darroch et al., 2018) which appear in the fossil record $\sim 575$ million years ago and contain some of the oldest animals in the fossil record (Xiao and Laflamme 2009; Budd and Jensen 2017; Bobrovskiy et al., 2018; Dunn et al., 2018, 2021; Hoyal Cuthill and Han 2018; Wood et al., 2019). The morphologies of Ediacaran organisms from Newfoundland and the United Kingdom have few clear points of homology with living animal lineages or Phanerozoic fossil groups, which has historically limited our understanding of their phylogenetic affinities and hampers our understanding of the functional ecology of these organisms (Laflamme et al., 2013; Liu et al., 2015). 
The Ediacaran communities of Eastern Newfoundland are dominated by the perhaps most distinct members of the Ediacaran macrobiota-the sessile, frondose rangeomorphs (Narbonne and Gehling 2003; Narbonne 2005). Rangeomorphs are characterised by a "fractal" branching architecture (Narbonne 2004; Hoyal Cuthill and Conway Morris 2014), and which increasing data supports as a clade of stem-group eumetazoans (Hoyal Cuthill and Han 2018; Dunn et al., 2021). Rangeomorphs numerically dominate these lateEdiacaran sea floors, but they lived alongside a number of different groups, the most abundant of which are the arboreomorphs (Clapham et al., 2003; Xiao and Laflamme 2009). These are similarly frondose, but unlike the rangeomorphs which can possess many orders of hierarchical branching, Newfoundland arboreomorphs possess only two orders (Laflamme et al., 2004; Laflamme and Narbonne 2008; Laflamme et al., 2018). Non-frondose fossils are also present, though rare in these fossil deposits-the most well-known is Thectardis, a conical to triangular organism which has been interpreted as a sponge (Clapham et al., 2004; Sperling et al., 2011).

Of these groups, rangeomorphs are not only the most diverse but display the greatest anatomical variation (Shen et al., 2008; Xiao and Laflamme 2009). Some rangeomorphs are preserved as single fronds (e.g., Charnia), but others were bushy (e.g., Bradgatia), spindle-shaped (e.g., Fractofusus) or arborescent (e.g., Primocandelabrum) (Gehling and Narbonne 2007; Bamforth et al., 2008; Flude and Narbonne 2008; Bamforth and Narbonne 2009; Dunn et al., 2019). Rangeomorph branches differentiated directly from one another or from a central stalk (Dunn et al., 2019) and some rangeomorphs additionally exhibited a naked stem that elevated the frond into the water column (Laflamme et al., 2012). Most rangeomorphs possessed a spheroidal-discoidal holdfast that anchored them within the sediment (Laflamme et al., 2004; Burzynski and Narbonne 2015), attaching the organism to the substrate and from which the stem or frond derived. Previous functional studies have demonstrated that the high surface area of the repeatedly branched frond maximised nutrient or gas exchange (Laflamme et al., 2009; Sperling et al., 2011; Liu et al., 2015). The phylogenetic relationship between frondose rangeomorphs and the coeval arboreomorphs is currently unclear (Dececchi et al., 2017; Hoyal Cuthill and Han 2018); some have argued that arboreomorphs are members of the Rangeomorpha (Brasier and Antcliffe 2009), but clear anatomical differences between at least some arboreomorphs and rangeomorphs mean that this view is not universally held, with others suggesting that overtly similar gross morphologies may have arisen through convergence (Laflamme et al., 2018). Indeed, in the modern, a sessile, frondose bodyplan is found in myriad different groups, such as ferns, cnidarians and bryozoans and has been acquired through different developmental processes, demonstrating that such a bodyplan can be the product of similar ecologies or function and is not necessarily indicative of close phylogenetic relationship.

Stems were originally thought to facilitate height-driven tiering in Avalonian communities, allowing taller fronds to reach higher-velocity conditions (Clapham and Narbonne, 2002; Ghisalberti et al., 2014), but more recent work has suggested that not all communities were tiered and that increased height may have additionally functioned in offspring dispersal (Mitchell and Kenchington 2018). Thickening of the stem close to the holdfast-optimisation of the stem as a cantilever beam-is observed in cnidarians (Koehl 1977a, b), and crinoids (Baumiller and Ausich 1996), where it permits orientation of the crown with the aboral surface facing the flow, initiating aboral inflow and recirculation (Dynowski et al., 2016). Rangeomorphs have been documented as showing a basal thickening of the stem and so may have functioned in the same way (Kenchington and Wilby 2017). By examining the different functional ecology of stemmed and non-stemmed organisms, we can investigate what the advantages of stems were in Ediacaran organisms.

These fossils are found preserved within turbiditic sequences, under thin layers of ash which blanketed large swathes of sea floor and smothered thousands of macro-organisms in a single event bed (Wood et al., 2003). Communities are exceptionally preserved and provide a near-census record of the benthos (Wood et al., 2003). This in-situ preservation, combined with the sessile habit of the organisms, means that detailed spatial ecological analyses can be used to investigate reproductive strategies (Mitchell et al., 2015), taxonomy (Mitchell et al., 2018), community interactions (Mitchell and Butterfield 2018) and evolutionary drivers (Mitchell et al., 2019, 2020), and in this study supplement functional ecology analyses of the organisms.

Here, we use statistical analyses of the orientations of 8 taxa from the E surface, Mistaken Point, Newfoundland: Beothukis, Bradgatia, Charniodiscus procerus, Charniodiscus spinosus, Plumeropriscum, Primocandelabrum, Thectardis, and Fractofusus. We determine the extent to which orientation distributions of populations of complete specimens, stems and fronds are randomly, normally and/or uniformly distributed, and how many sub-groups within each population exist. Where taxa exhibit multi-modal orientation distributions, we use random labelling spatial analyses to determine whether there are any spatial patterns to taxa orientations. These analyses enable us to investigate how morphological features, such as stems and number of folia influenced the stability of these organisms in the ancient oceans and their ability to withstand burial events of differing magnitudes.

\section{Geological Setting}

The Avalon Assemblage records the evolution of deep marine metazoan communities from the $\sim 574 \mathrm{Ma}$ Drook Formation (Matthews et al., 2021), to the late Ediacaran Bradgate Formation [556.6 $\pm 6.4 \mathrm{Ma}$, (Noble et al., 2015)]. One of the three assemblages originally proposed by Waggoner 2003, it traces the marine margin of the Avalonian Terrane through the British Isles and Newfoundland. In both regions, sedimentation was dominated by turbidite deposition (Wood et al., 2003; Noble et al., 2015). Throughout the Newfoundland succession, there is a transition in tectonic setting and depositional character (Figure 1), from the basin plain setting of the lower Conception Group to the shallowing-upwards slope 

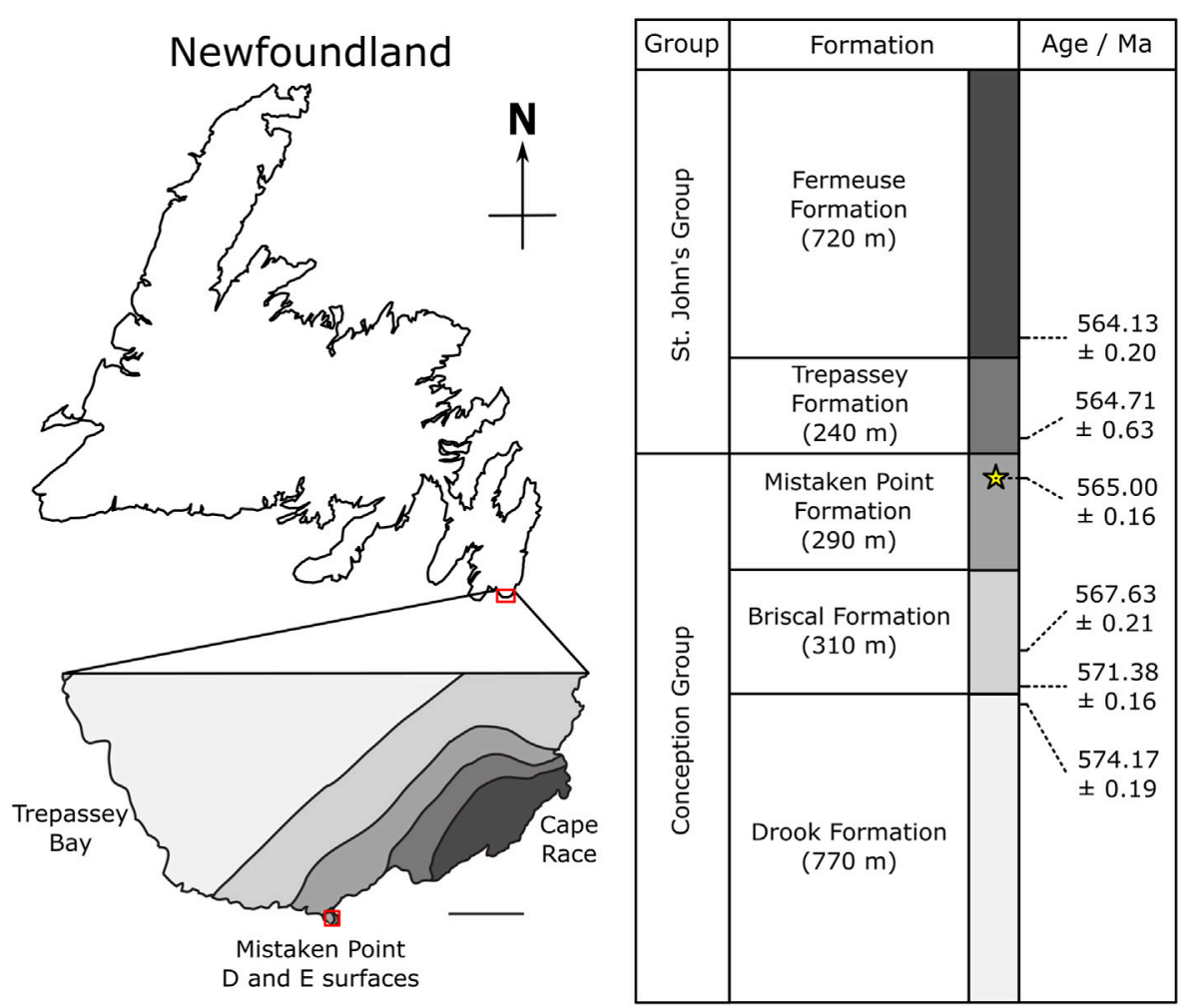

FIGURE 1 | Geological Map after Liu (2016) and Matthews et al. (2021) showing the location of the E surface, Mistaken Point within Newfoundland, Canada, and the stratigraphy and age from (Matthews et al., 2021).

setting of the upper Conception and St John's groups, with a concomitant increase in depositional energy and rate of deposition and a basinwards progradation of the locus of sedimentation (Wood et al., 2003; Matthews et al., 2021).

The Mistaken Point Formation is dominated by thick-bedded, mud-rich and ashy turbidites, punctuated by tuffaceous horizons (Wood et al., 2003; Ichaso et al., 2007; Matthews et al., 2021). The bed over the E surface has a thin, coarse crystal tuff, a lower graded portion and an upper portion that consists of alternating dark-light bands (above the chlorite-carbonate band; (Supplementary Figure S4; Matthews et al., 2021). The exact mode of emplacement of the tuffaceous horizons was long thought to be primarily from water-lain ashfall events (where ashy material enters the basin, and gradually settles out through the water column). However, recent work suggests that at least some of these horizons were instead the product of ashy turbidites, and that they contain variable proportions of volcaniclastic (eruptive and/or unlithified reworked) and epiclastic (lithified and reworked) material (Noble et al., 2015; Kenchington et al., 2018; Matthews et al., 2021).

The mode of emplacement has direct implications for understanding the process that felled the fronds within the palaeocommunities, and therefore their preserved orientations. If the tuffs were water-lain, they are not necessarily associated with a gravity-driven flow, and accordingly the fronds were interpreted as having been felled by basin contour-parallel currents (Wood et al., 2003). However, if the smothering ashes are a product of turbidity flows, then it is likely that the fronds were felled by these same flows (Matthews et al., 2021). In the specific case of the $\mathrm{E}$ surface, however, there is no contention that there is a gravity-driven flow origin for the alignment of fronds on the E Surface (F12 of Wood et al., 2003; Matthews et al., 2021) though this may be atypical for the Mistaken Point Formation (Wood et al., 2003).

\section{Gravity Flows and Their Expression in the Rock Record}

Turbidites are the lithological record of deposition via sedimentladen turbidity currents, and exist on a continuum with other gravity-driven flows and their deposits (Haughton et al., 2009; Talling et al., 2012). The lack of evidence of fluvial input, together with the slump horizons that occur throughout the Mistaken Point Formation (Wood et al., 2003), suggests that the source of the flows in the Mistaken Point Formation are more likely to be those dominantly sourced from slope failure (slumping), rather than rivers. Therefore, here we focus only on the former. Gravity flow behaviour, and thus classification, is principally driven by two factors: the fraction of cohesive components within the sediment, and the overall concentration of sediments within the flow (e.g., Haughton et al., 2009). Higher sediment concentrations, and higher fractions of cohesive components (clay minerals and reworked muds), act to dampen turbulence at the sediment-water interfaces (Cantero et al., 2012; Talling 
et al., 2012), and within dilute turbidity currents (Baas and Best 2002; Baas et al., 2009).

The coarse tuff immediately above the E surface could be indicative of particle sorting and winnowing within the more turbulent head of the turbidity current (Sparks and Wilson 1983), while the structure within the rest of the bed is consistent with the hybrid flow model of Haughton et al., 2009 (Matthews et al., 2021). On a broad scale, this mixed/hybrid flow interpretation may be reflected in the increased turbidite thickness within the Mistaken Point Formation [previously interpreted as turbidite ponding, (Ichaso et al., 2007)]. Surface weathering, synsedimentary and early diagenetic alteration of the volcaniclastic source for the Mistaken Point turbidites would have produced a clay-rich source sediment (cf. Kiipli et al., 2007), enhanced by addition of deposition from nepheloid plumes or as hemipelagic fallout (cf. Kenchington et al., 2018). This high clay content and high sediment load would have increased the cohesion within the flow and so dampened its turbulence (see Shringarpure et al., 2012), potentially generating conditions conducive to internal laminar flow (Fisher 1983), while dilution of the head of the turbidity flow likely brought concentrations below the threshold for a laminar-dominated regime (similar to the high-density turbidity or lower density mixed flows of Haughton et al., 2009), with turbulent conditions within the head of the turbidity flow.

As a flow moves down a slope, it can change character and concentration, reflected in different depositional products (Houghton et al., 2009). For example, after slumping, entrainment of water rapidly dilutes the head of the turbidity flow, inhibiting sediment-induced turbulence dampening (Hallworth et al., 1993; Cartigny et al., 2013). In contrast, entrainment of clay-rich material would have the opposite effect. Differential dilution-driven turbulence often manifests as Kelvin-Helmholtz instabilities (Liu and Jiang 2014), wherein turbulent eddies rotate about a horizontal axis orthogonal to the direction of turbidity current propagation (see "roll waves" of Cartigny et al., 2013) -important when we are thinking about the processes controlling frond orientation.

\section{MATERIALS AND METHODS}

\section{Data Processing}

In this study we used mapped data from the E surface taken from Mitchell et al., 2019. Mitchell et al. LiDAR scanned the E surface using a Faro Focus $330 \mathrm{X}$ to ensure spatial accuracy was maintained over large areas. The LiDAR scans resulted in a 3D surface mesh of $1 \mathrm{~mm}$ resolution. In order to get sufficient resolution to resolve taxonomic identity, Mitchell et al. also laser scanned the E surface using a Faro Scan Arm v6LLP, resulting in surface meshes of $\sim 0.050 \mathrm{~mm}$ resolution. The high-resolution scanning was done in grids of $\sim 1 \mathrm{~m} \times 1 \mathrm{~m}$. Due to large file sizes, these high-resolution scans could not all be viewed simultaneously, so control points were marked in each highresolution scan, and in the LiDAR scan, enabling accurate combination of the high-resolution scans with the LiDAR surface data (performed using Geomagic 2015). A photomap was created by photographing the specimens along a horizontal and vertical grid, then using Agisoft Photoscan software v1.3.5 to create a photogrammetric render of the surface. The LiDAR scan was then imported into Photoscan, and the photographs aligned on the LiDAR scan to ensure large-scale accuracy. An orthomosaic of the surface was produced within Agisoft PhotoScan, from which the data was collected. The combination of LiDAR, LLP and photogrammetry enabled accurate retention of angle data between photographs, with minimal perspective projection distortion (Mitchell et al., 2019). Specimens were binned into 8 morphogroups: Beothukis - a unifoliate, spatulate-fronded rangeomorph, with a short-or absent-stem and holdfast (Brasier and Antcliffe 2009; Hawco et al., 2020; Figure 2A, C); Bradgatia-a multifoliate rangeomorph consisting of up to eight folia from a central branching point on an inferred holdfast (Boynton and Ford 1995; Flude and Narbonne 2008; Figure 2B); Charniodiscus procerus-a unifoliate arboreomorph possessing a circular holdfast, elongate stem, and a lanceolate frond (often laterally displaced) without fractal, rangeomorph-style branching (Laflamme et al., 2004; Figure 2A); Charniodiscus spinosus-a unifoliate arboreomorph with a large ovate frond, lacking rangeomorph-style branching, tipped with an elongate spine, connected to a large holdfast via a short cylindrical stem (Laflamme et al., 2004; Figure 2D); Fractofusus-a spindleshaped rangeomorph with bundled frondlets offset along a central axis (Gehling and Narbonne 2007; Mitchell et al., 2015; Figure 2F); Plumeropriscum-a multifoliate rangeomorph composed of at least nine first order branches furcating from an elongate cylindrical stem, attached to the substrate by a discoidal holdfast (Mason and Narbonne 2016; Figure 2F); Primocandelabrum - a multifoliate rangeomorph consisting of a large holdfast, elongate stem, and substantial crown composed of three first order branches (Hofmann et al., 2008; Kenchington and Wilby 2017; Figure 2G and Thectardis-an erect conical taxon lacking evidence of a holdfast (Clapham et al., 2004; Figure 2E). We used the size and orientation data from Mitchell et al. (2019) for Fractofusus. We identified 18 Beothukis, 52 Bradgatia, 61 C. procerus, 31 C. spinosus, 20 Plumeropriscum, 47 Primocandelabrum and 27 Thectardis and 1,593 Fractofusus across $85.42 \mathrm{~m}^{2}$ of the E surface bedding plane.

\section{Retrodeformation}

The E surface has undergone tectonic deformation so prior to any analyses, retrodeformation needs to be performed to re-engineer the organisms back to their in-death dimensions (Wood et al., 2003; Gehling and Narbonne 2007; Figure 3). To perform the retrodeformation, we collected the dimensions and orientations of 24 representative, large, discs across the E Surface (Supplementary Figure S1). Utilising a constant area retrodeformation method, the principal axis lengths for each disc were extracted. Following the methodology of Mitchell et al. (2015), a regression was fitted to determine the retrodeformation ratio $(1.75$, within the confidence interval (1.71 \pm 0.08) of Mitchell et al. (2015), which was applied across the entire E surface. To apply this retrodeformation, the annotated photosquares were aligned and stitched together in 


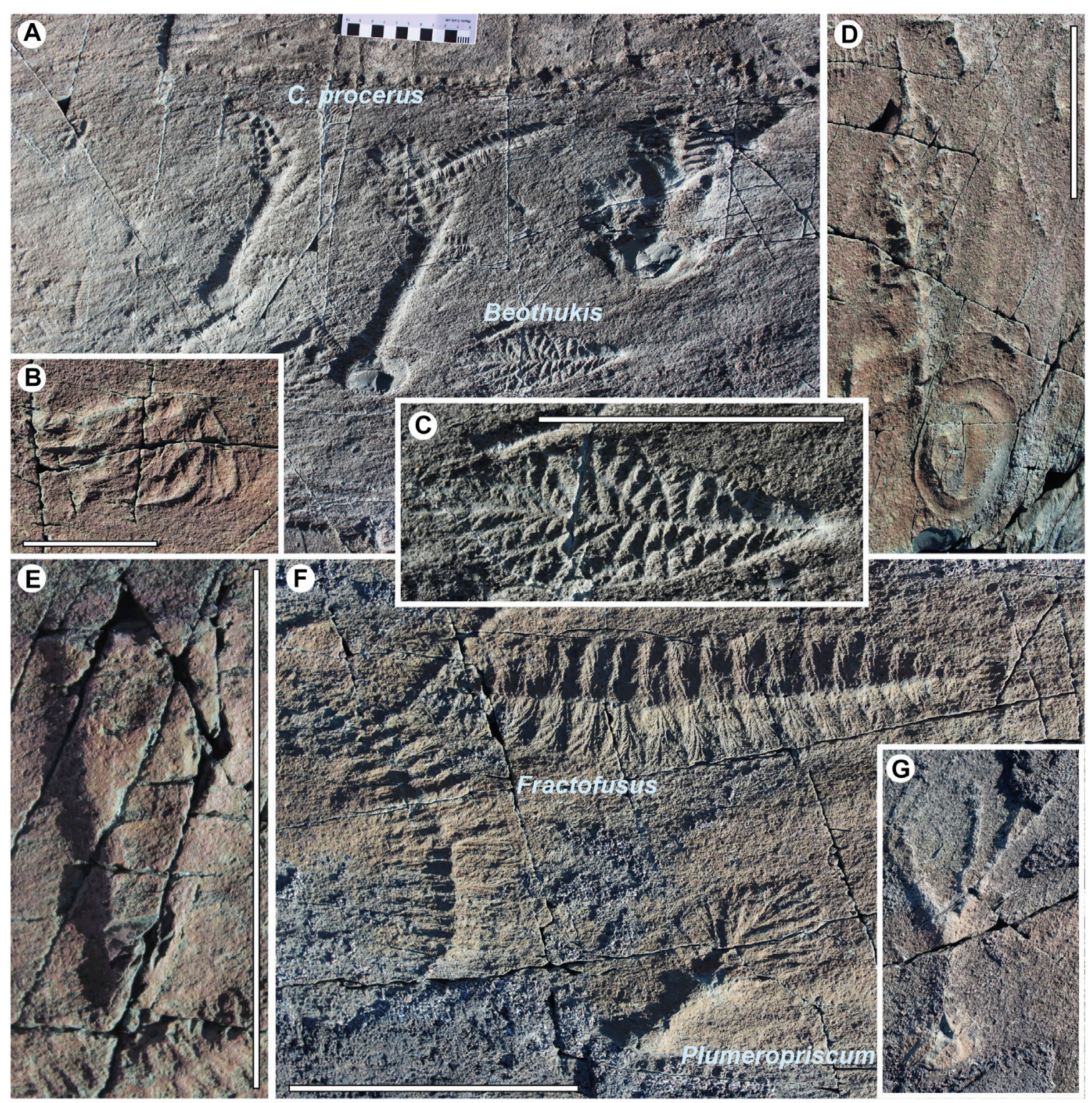

FIGURE 2 | E surface taxa included in this study. (A) Charniodiscus procerus and Beothukis and (B) Close up of Bradgatia (C) Beothukis (D) Charniodiscus spinosus (E) Thectardis, (F) Fractofusus and Plumeropriscum and (G) Primocandelabrum. Scale bar is $5 \mathrm{~cm}$.

Inkscape v0.92.4, and rotated to align the principal axes of the mean disc with the vertical and horizontal axes of the document-thus aligning the eigenvectors of retrodeformation with the axes of the document. From here, constant area retrodeformation can be characterised as a deformation, which can be achieved with shortening and elongation of the vertical and horizontal axes. The retrodeformed surface was then rotated to the original orientation. Overall, the photosquares were shortened by $26.7 \%$ along the eigenvector oriented $78.5^{\circ}$, and elongated $36.8 \%$ along the orthogonal eigenvector of $168.5^{\circ}$ (Supplementary Figure S1). We note that, whilst retrodeformation techniques have the potential to introduce error (Liu et al., 2011), the strong correlation of the regression
$\left(R^{2}=0.86\right)$ (Supplementary Figure $\left.\mathbf{S 1}\right)$ suggests that our retrodeformation technique is suitable for the spatial scale of the mapped E Surface. The orientation measurements are different for Fractofusus because unlike the frondose organisms there is no differentiation between the top and bottom half of the organism, such as a disc. As such, the angles are limited to a $180^{\circ}$ range of $0^{\circ}$ to $180^{\circ}$ with the angle of e.g., $200^{\circ}$ being equivalent to $20^{\circ}$.

\section{Statistical Analyses}

For each taxon population we performed four tests in R v4.0.4. To test for non-uniform distributions of orientation data we used the Rao's Spacing Test of Uniformity using the package CircStats 


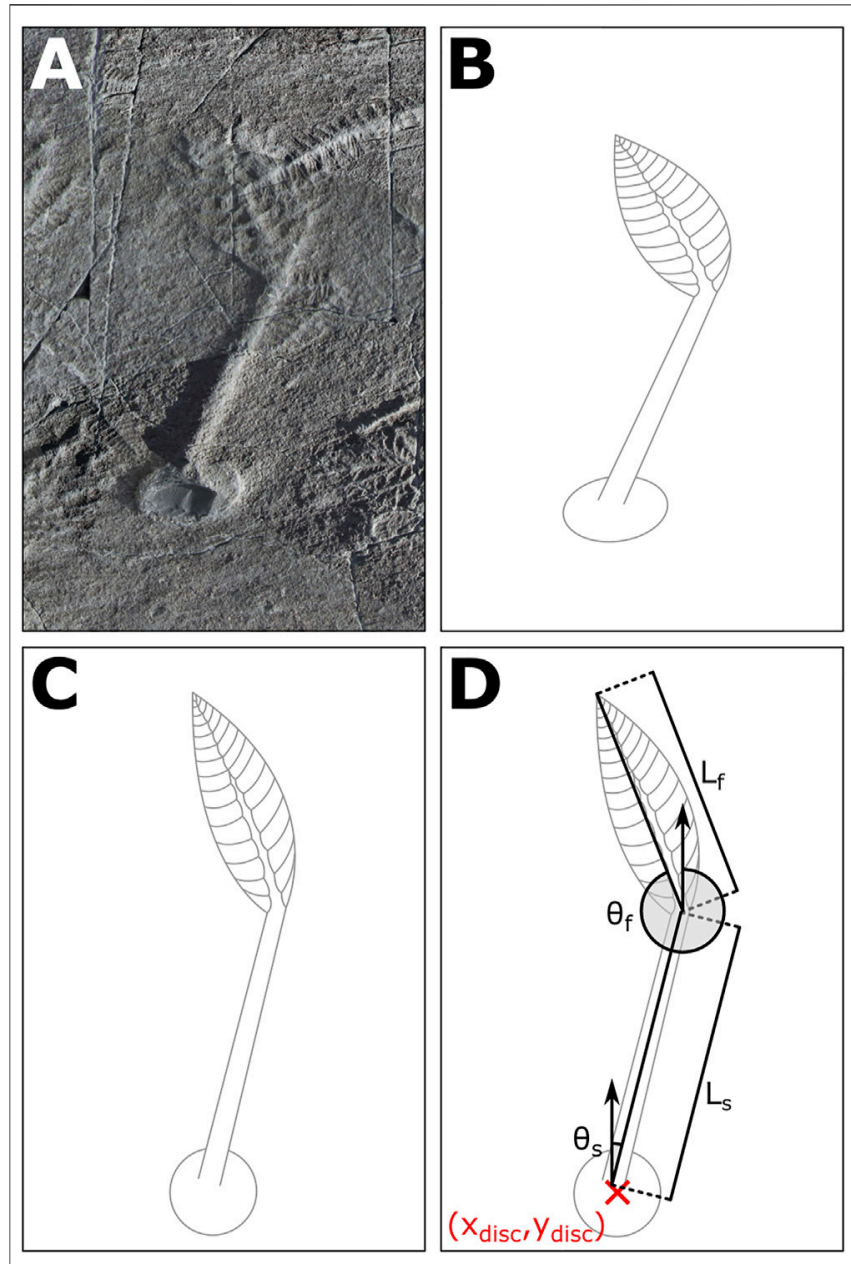

FIGURE 3 | Specimen measurements. An example specimen (A) showing the retrodeformation of the disc (B,C, and $\mathbf{D})$ the measurements collected for each specimen. The position of the disc is denoted as $\left(\mathrm{x}_{\text {disc }}, \mathrm{y}_{\text {disc }}\right)$; the length of the frond as $L_{f}$; the length of the stem as $L_{s}$; the angle of the frond as $\theta_{\mathrm{f}}$; and the angle of the stem as $\theta_{\mathrm{s}}$

v0.2-6 (Agostinelli and Agostinelli 2018), with a $p$-value $<0.05$ indicating a non-uniform distribution (Rao 1976). For our data, a significant $p$-value indicates non-random felling of organisms, with some orientations exhibiting a greater frequency than would otherwise be expected from random felling. In order to test for multimodal distributions within angular data we used the Hermans-Rasson test (HR test of Landler et al., 2019) using the package CircMLE v3.0.0 (Fitak and Johnsen 2017). Where multi-modal distributions were found, the mean values for each peak were identified utilising the Gaussian finite mixture modelbased clustering algorithms of mclust v5.4.7 (Fraley and Raftery 2017). To account for the circular nature of angular data, the density distribution was inspected and split at a minimum to ensure any peaks coincident with $0^{\circ}$ were not bisected. This split produced a continuous $360^{\circ}$ density distribution with no assumed peak bisection. When more than one distribution was present (i.e. bidirectional distributions), the data were partitioned into two peaks, whilst unimodal distributions (including those found to be composed of multiple coincident distributions) were left unpartitioned. The circular equivalent to a normal distribution is the von Mises distribution, tested using a Watson's goodness of fit (Agostinelli and Agostinelli 2018). A statistically significant $p$-value output corroborates a von Mises distribution-where a significant von Mises distribution was found, the models of Schnute and Groot (1992) were employed to test for a variety of modelled orientation scenarios. For bimodally-distributed taxa, the constituent distributions were partitioned and frond lengths cross-compared utilising a Mann-Whitney test. Statistical significance would suggest non-uniform sampling from the same parent population; in essence, the orientation-partitioned data would exhibit different frond length distributions.

In order to investigate the spatial distribution of populations which exhibited significant multi-modal orientations, random labelling analyses (RLA) were used. RLA are a type of spatial point process analysis whereby the position of each point (here fossil specimen) is kept constant, but the label (here the orientation group) is randomly permutated about the points (Illian et al., 2008). As such, RLAs do not directly measure the aggregation or segregation between labels (here orientation patterns), so do not test the processes that resulted in labels, but instead measure the differences in spatial distributions of the labels independently of the positions of the fossil specimens (cf. Mitchell et al., 2018). Spatial distributions are commonly described using pair correlation functions (PCFs) which describe how the density of points (i.e. fossil specimens) changes as a function of distance from the average specimen (e.g., Illian et al., 2008). RLAs assess the differences between two characters (orientation group 1 or group 2) of the populations by calculating variations between PCFs by considering the Difference test and the Quotient test (Wiegand and Moloney 2013). The Difference test is the calculation of the difference the distribution of each group in turn $\left(\mathrm{PCF}_{11}\right.$ is the distribution of group 1 and $\mathrm{PCF}_{22}$ the distribution of group 2) i.e. $\mathrm{PCF}_{11}-\mathrm{PCF}_{22}$. These differences test the relative aggregation (or segregation) of the spatial distributions of the orientations compared to each other. If $\mathrm{PCF}_{11}-\mathrm{PCF}_{22}=1$ then the orientation groups are randomly distributed about the surface. The Quotient test calculates how the relative group (Diggle et al., 2005) changed with respect to the total density (i.e. the joined distribution of both group 1 and group 2). The distribution of group 1 relative to the joined groups $\mathrm{PCF}_{1,1+2}$, and group 2 relative to the joined groups $\mathrm{PCF}_{2,2+1}$ with the Quotient test as the calculation: $\mathrm{PCF}_{1,1+2}-\mathrm{PCF}_{21} / \mathrm{PCF}_{2,2+1}$. If $\mathrm{PCF}_{12} /$ $\mathrm{PCF}_{1,1+2}-\mathrm{PCF}_{21} / \mathrm{PCF}_{2,2+1}>0$ then group 2 is mainly located in areas with high density of the joint pattern, and group 1 is in low density areas (i.e., group 2 has more neighbours than group 1 . If this Quotient is significantly non-zero, then the process underlying the characters is density-dependent. In order to test whether any observed patterns were significantly different from a random distribution we follow Mitchell and Harris 2020 and use two different methods, which are commonly used to establish acceptance or rejection of the null hypotheses for ecological data (e.g., Illian et al., 2008 and references therein): 1) Monte Carlo simulations, and 2) Diggle's goodness-of-fit test $p_{d}$, which represents the total squared deviation between the observed pattern and the simulated pattern across the studied 
TABLE 1 | Results of uniformity tests, with 5\% significance levels used to indicate rejection of the null models i.e., non-random orientations for the Rao's spacing and Hermans-Rasson tests and von Mises distribution (normally distributed orientation data) for the Watson's test.

\begin{tabular}{|c|c|c|c|c|}
\hline Taxa & Measurement & Rao's Test $p$-value & Hermans-Rasson test $p$-value & Watson's Test $p$-value \\
\hline Beothukis & Fronds & $<0.001$ & 0.0001 & $>0.10$ \\
\hline \multirow[t]{2}{*}{ Bradgatia } & Fronds & $<0.001$ & 0.0001 & $>0.10$ \\
\hline & & & & $<0.05$ \\
\hline \multirow[t]{2}{*}{ C. procerus } & Stems & $<0.001$ & 0.0001 & $>0.10$ \\
\hline & Fronds & $<0.001$ & 0.0001 & $>0.10$ \\
\hline \multirow[t]{2}{*}{ C. spinosus } & Stems & $<0.001$ & 0.0001 & $>0.10$ \\
\hline & Fronds & $<0.001$ & 0.0001 & $>0.10$ \\
\hline Fractofusus & Length & $<0.001$ & 0.0010 & $<0.01$ \\
\hline \multirow[t]{2}{*}{ Plumeropriscum } & Stems & $<0.001$ & 0.0001 & $>0.10$ \\
\hline & Fronds & $<0.001$ & 0.0001 & $>0.10$ \\
\hline \multirow[t]{2}{*}{ Primocandelabrum } & Stems & $<0.001$ & 0.0001 & $<0.01$ \\
\hline & Fronds & $<0.001$ & 0.0001 & $<0.05$ \\
\hline \multirow[t]{2}{*}{ Thectardis } & Cones & $<0.010$ & 0.0001 & $>0.10$ \\
\hline & & & & $>0.10$ \\
\hline
\end{tabular}

Where more than one cohort is found (such as for Bradgatia) there will be a Watson's Test for each cohort.

TABLE 2 | Cohort analyses for each morphogroup orientation distribution. $\sigma$ indicates the standard deviation of each cohort with respect to the provided mean orientation. Where all cohorts within a population have equal standard deviation (such as Beothukis) a single $\sigma$ is given, and where each $\sigma$ varies according to the cohort (unequal variance) then a value is given for each cohort. Note that the Fractofusus data represents the simplest of two statistically-indistinguishable BIC models (Supplementary Figure S2). Note for C. spinosus and Primocandelabrum the cohorts of one represents outliers, which were not well resolved by cohort-analyses (Supplementary Figure S3).

\begin{tabular}{|c|c|c|c|c|c|}
\hline Taxa & Measured & $\mathbf{N}$ & Mean Orientation ( $\left.{ }^{\circ}\right)$ & $\sigma$ & Proportion (\%) \\
\hline \multirow[t]{5}{*}{ Beothukis } & Fronds & 1 & 95 & 2.45 & 5.56 \\
\hline & & 4 & 135 & & 22.22 \\
\hline & & 5 & 161 & & 27.78 \\
\hline & & 3 & 172 & & 16.67 \\
\hline & & 5 & 185 & & 27.78 \\
\hline \multirow[t]{2}{*}{ Bradgatia } & Fronds & 30 & 15 & 26.79 & 57.69 \\
\hline & & 22 & 188 & & 42.31 \\
\hline \multirow[t]{2}{*}{ C. procerus } & Stems & 61 & 195 & 18.89 & 100.00 \\
\hline & Fronds & 61 & 192 & 30.23 & 100.00 \\
\hline \multirow[t]{4}{*}{ C. spinosus } & Stems & 30 & 190 & 30.87 & 96.77 \\
\hline & & 1 & 326 & NA & 3.23 \\
\hline & Fronds & 30 & 183 & 24.83 & 96.77 \\
\hline & & 1 & 328 & NA & 3.23 \\
\hline \multirow[t]{4}{*}{ Fractofusus } & Fronds & 206 & $11(191)$ & 10.47 & 12.93 \\
\hline & & 602 & $72(252)$ & 24.83 & 37.79 \\
\hline & & 517 & $126(306)$ & 18.96 & 32.45 \\
\hline & & 268 & $167(347)$ & 7.28 & 16.82 \\
\hline \multirow[t]{2}{*}{ Plumeropriscum } & Stems & 20 & 178 & 16.73 & 100.00 \\
\hline & Fronds & 20 & 177 & 17.26 & 100.00 \\
\hline \multirow[t]{7}{*}{ Primocandelabrum } & Stems & 42 & 183 & 13.74 & 89.36 \\
\hline & & 3 & 237 & 13.74 & 6.38 \\
\hline & & 1 & 11 & NA & 2.13 \\
\hline & & 1 & 119 & NA & 2.13 \\
\hline & Fronds & 45 & 187 & 19.05 & 95.74 \\
\hline & & 1 & 14 & NA & 2.13 \\
\hline & & 1 & 98 & NA & 2.13 \\
\hline \multirow[t]{2}{*}{ Thectardis } & Cones & 7 & 17 & 33.00 & 25.93 \\
\hline & & 20 & 199 & & 74.07 \\
\hline
\end{tabular}

distances (Diggle et al., 2005). For each RLA test performed, 999 Monte Carlo simulations were used to generate simulation envelopes around the random PCF difference (e.g.,
$\left.\mathrm{PCF}_{11}-\mathrm{PCF}_{22}=0\right)$ and the $p_{d}$ values were calculated using Diggle's goodness-of-fit test. If the observed test (either Difference or Quotient) fell outside the RLA generated Monte 

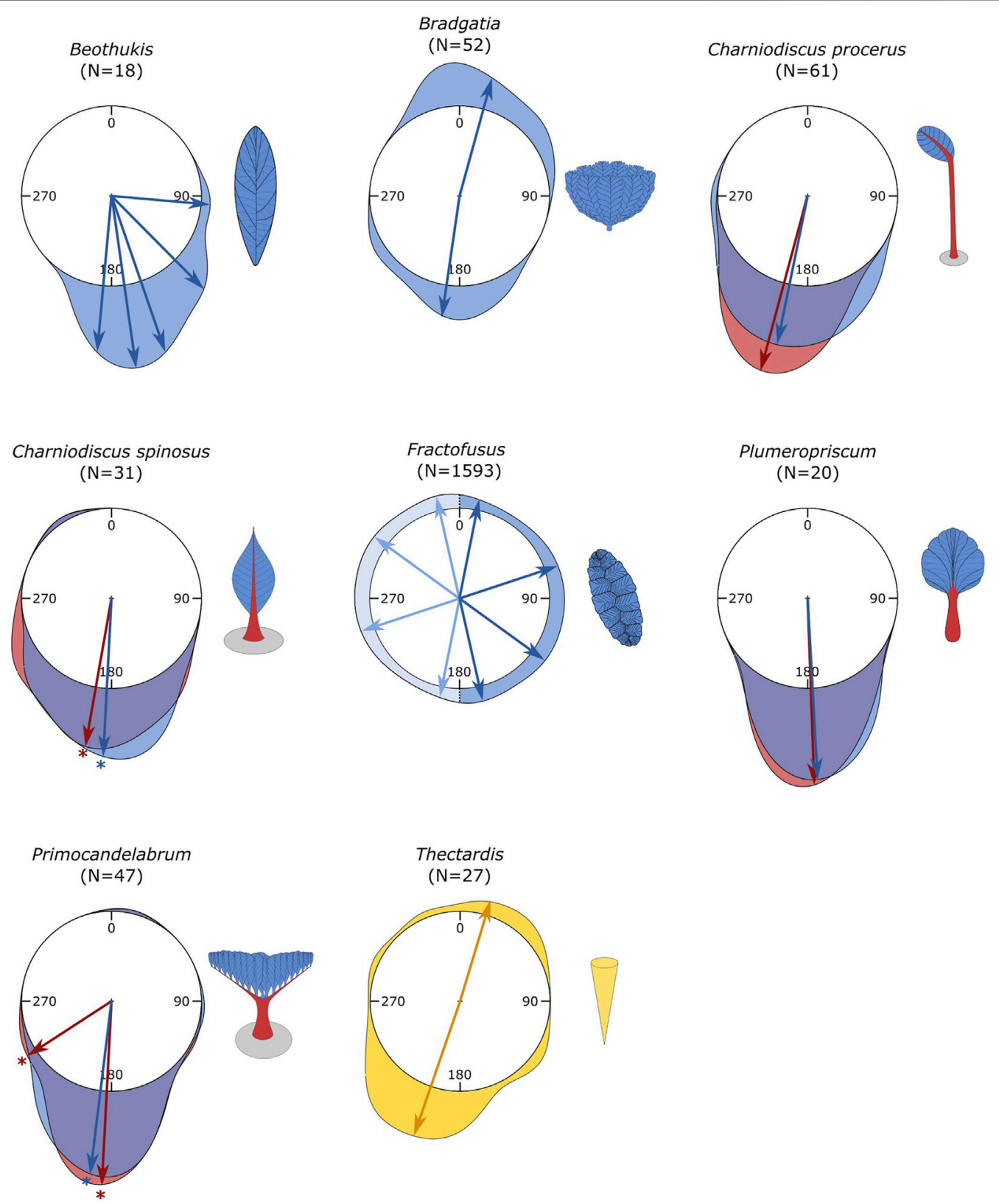

FIGURE 4|Rose diagrams of the population. Blue indicates frond orientations, Red, the stem orientations and yellow for Thectardis. Arrows indicate the mean(s) of the cohort orientation distributions, with starred arrows indicating where outliers have been removed. With Fractofusus the pale blue indicates circular duplication of the pattern, because it is not possible to polarise along the main body axis.

Carlo envelopes and also had $p_{d}<0.1$, then the distributions were found to be significantly different. RLAs were performed in Programita (Wiegand and Moloney 2013).

\section{RESULTS}

For all taxa we found statistically significant non-random distributions using the Rao's Spacing Test of Uniformity and the improved Hermans-Rasson-(all $p<0.01$, Table 1). The majority of taxa exhibited a non-von Mises (i.e., non-normal) distributions as per the Watson's test (Table 1). One Bradgatia cohort $(p<0.05)$, and the Primocandelabrum stems $(p<0.01)$, and fronds $(p<0.05)$ exhibited von Mises distributions (Table 1). The von Mises distributions for Primocandelabrum enabled model fitting to the orientation distributions of Primocandelabrum, which were found to exhibit bi-modal distributions (Supplementary Figure S2).

Analyses of the number of cohorts within each morphogroup orientation distribution varied between 1 and 5 (Table 2; 

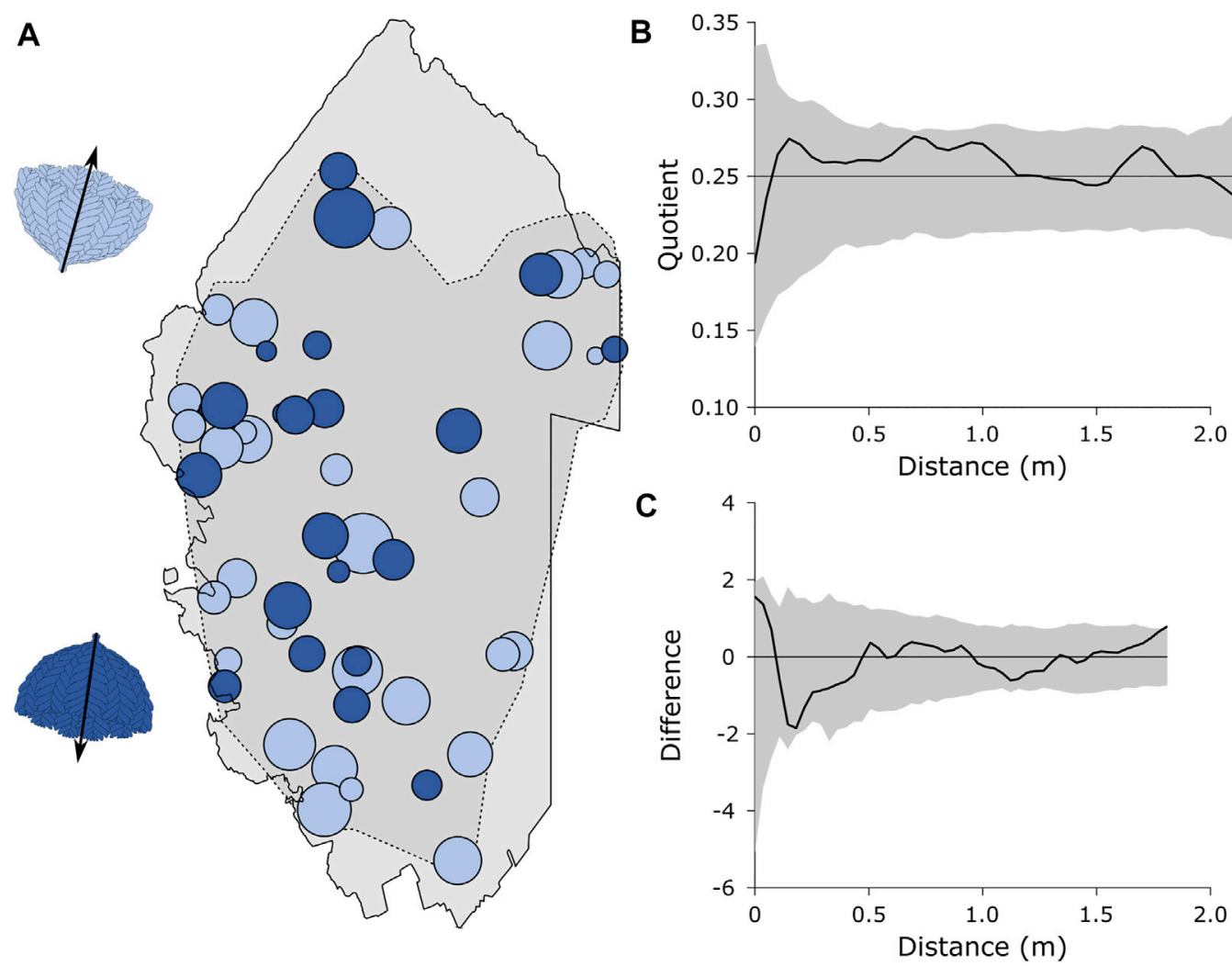

FIGURE 5|Random labelling analyses for the two cohorts of Bradgatia. (A) Mapped Bradgatia on the E surface, showing the two directions in light and dark blue. The diameter of the circles represents the height of the specimens. Light grey area is the retrodeformed outline of the $\mathrm{E}$ surface.

Figure 4). For C. procerus and Plumeropriscum, the stems and fronds exhibited uni-modal distributions, with similar mean orientations of $195^{\circ}$ and $192^{\circ}$ for C. procerus stems and fronds and $178^{\circ}$ and $177^{\circ}$ for Plumeropriscum (Table 2; Figure 4). The majority $(96.77 \%)$ of C. spinosus stems and fronds exhibited a unimodal distribution $\left(190^{\circ}\right.$ and $183^{\circ}$ respectively), with a single outlier orientated at $326^{\circ}$ for stem and $328^{\circ}$ for frond (Table 2; Figure 4, Supplementary Figure S3). Similarly, Primocandelabrum specimens exhibit a unimodal distribution for their fronds $\left(95.74 \%, 187^{\circ}\right)$ and with a minor bimodal component for the stems $\left(89.36 \%, 183^{\circ} ; 6.38 \%, 237^{\circ}\right)$, with two singleton outliers, and frond at $14^{\circ}$ and the second with its stem at $119^{\circ}$ and frond at $98^{\circ}$ (Table 2; Figure 4, Supplementary Figure S3). Thectardis and Bradgatia exhibited bi-modal distributions, with different distributions indicated by the mean orientations being notably different between the two groups, in contrast to Primocandelabrum and C. spinosus (Table 2; Figure 4). The majority of Bradgatia specimens (57.69\%) formed a cohort with the mean orientation of $15^{\circ}$, with the remainder (42.31\%) within the cohort at $188^{\circ}$ (Table 2; Figure 4). The majority of Thectardis specimens (74.07\%) formed a cohort with the mean orientation of $199^{\circ}$, with the remainder $(25.93 \%)$ within the cohort at $17^{\circ}$ (Table 2; Figure 4). The distribution of sampled Beothukis specimens formed 5 distinct cohorts
(Table 2), with one specimen notably different at $95^{\circ}$ to the other four cohorts, which had similar mean orientations with the unimodal taxa orientations. The small number of specimens within the Beothukis distributions indicates that the relatively high number of cohorts could be an artefact of small sample sizes. Fractofusus exhibited a multi-modal distribution, with four cohorts at $11^{\circ}, 72^{\circ}, 126^{\circ}$ and $167^{\circ}$ within a $180^{\circ}$ distribution (Table 2; Figure 4).

Inspection of the distributions in Figure 4 shows that while the number of statistically significant cohorts within each taxon varies, the stemmed taxa (C. spinosus, C. procerus, Plumeropriscum and Primocandelabrum) and Beothukis were all orientated in similar directions, while Bradgatia and Thectardis had a significant proportion of specimens with an antipodal orientation (Table 2; Figure 4). While the mean orientations of the multiple Beothukis cohorts were all tightly clustered, showing clear directionality in a single direction, the Fractofusus mean orientations were evenly distributed across the range, with no such directionality (Figure 4).

Analyses of the bimodally distributed taxa found no significant differences mean frond length for Bradgatia $(p=0.1850)$, or cone length for Thectardis ( $p=0.4547$ ) between cohorts. Bradgatia was the only taxon that exhibited significant bidirectionality in numbers sufficient for RLA (Figure 5A). The Quotient test RLA, which describes the relative density dependence of different factors within a spatial population found that there was no 
density dependence between the two Bradgatia orientation groups $\left(p_{d}=0.8040\right.$, Figure 5B). The Difference test RLA, which tests for the difference between the spatial distributions of the two orientation groups, were not significantly different $\left(p_{d}\right.$ $=0.4104$, Figure 3C), although the observed difference was close to the outside the simulation envelope which could indicate a larger spatial scale pattern not captured within out data.

\section{DISCUSSION}

The orientation distributions of fossil specimens are well established as a mechanism to indicate palaeocurrent directions (Toots 1965; Jones and Dennison 1970; Ichaso et al., 2007). The orientation distribution of a given taxon depends on its mode of life, with erect benthic organisms exhibiting strong directionality, in contrast to non-erect organisms which have limited directionality (Toots 1965; Jones and Dennison 1970; Smith 1980; Demko 1995). These explanations of orientation distributions have been used to understand the mode-of-life of Ediacaran taxa, with qualitative examination of Fractofusus specimens showing even orientation distribution suggestive of a reclining mode of life (Gehling and Narbonne 2007). In contrast, Ediacaran fronds such as Charniodiscus and Charnia have been interpreted as erect organisms, due to the morphological similarities to extant benthos such as sea pens (Seilacher 1992; Laflamme and Narbonne 2008; Laflamme et al., 2012) and-crucially-the orientation of these fronds are noted to have a strongly preferred orientation, suggested to be aligned to the contourparallel current which felled them (Wood et al., 2003; Narbonne 2005; Ichaso et al., 2007; Laflamme et al., 2012). Strongly orientated organisms have been interpreted as erect because an organism attached to the seafloor at a single point will have the majority of its body pulled by the current, orientating it with its long axis parallel to this current (Hofmann et al., 2008). In contrast, if an organism is reclining on the substrate, it will not be subject to such currents, so will not display strong orientations (Gehling and Narbonne 2007; Bamforth and Narbonne 2009; Mitchell et al., 2015).

The relationship between fossil orientation and mode-of-life is pertinent because there has recently been revived debate surrounding the nature of the life habit of the Ediacaran rangeomorphs (e.g., McIlroy et al., 2020). Where fronds have historically been interpreted as displaying a mixture of upright and recumbent lifestyles (Ford 1958; Laflamme and Narbonne 2004; Laflamme and Narbonne 2008; Wilby et al., 2011), recent work has posited that recumbent lifestyles are more likely for some rangeomorph fronds. Orientation analyses allows us to test between these two different life habits in a statistically robust way. This study reflects the most statistically rigorous attempt to quantitatively test the orientation distributions of multiple E surface taxa, and quantify differences in orientations between the stems and fronds of these taxa. We find significant differences in felling behaviour between the stemless Bradgatia (sensu Flude and Narbonne 2008) and Thectardis (in broad agreement with Clapham et al., 2004), Fractofusus (Gehling and
Narbonne 2007), and all other taxa (Beothukis, the arboreomorphs, Primocandelabrum, and Plumeropriscum), which show unidirectional felling all oriented towards the south. Fractofusus shows no notable directionality in any direction, whereas orientation distributions of Bradgatia and Thectardis both exhibit evidence of bidirectional felling. We found no significant height/sized-based correlations with orientation or outliers. Our results confirm the qualitative results of previous authors (Wood et al., 2003; Narbonne et al., 2005; Gehling and Narbonne 2007; Laflamme et al., 2012) whereby frondose taxa such as Beothukis, Charniodiscus and Primocandelabrum were erect in the water-column, anchored to the sea-floor, while Fractofusus lived close to the substrate in a reclined habit. Our results do not support recent suggestions that the fronds like Beothukis reclined on the sediment in life (McIlroy et al., 2020). The orientation distributions we find for Bradgatia and Thectardis are also consistent with an upright mode of life (Clapham et al., 2004; Flude and Narbonne 2008) and felling in a (bidirectional) current. All of our results and interpretations are based on the behaviour of the majority of specimens within a taxon, and confirm the utility of populations of specimens rather than outliers to infer the ecology for the entire population of a given taxon (e.g., Benhadi-Marín 2018). Describing population distributions enables intra-specific variability to be captured, and thus enables comparison between populations. Indeed, it is not possible to compare the orientations of two specimens in a statistically rigorous and robust way without accounting for intra-specific variability, i.e., without quantifying the population behaviour. There are, notably, multiple cohorts within the orientation distributions of Beothukis. However, while $C$. procerus, for example, exhibits different mean orientation directionality to Beothukis, the 95\% confidence interval (as given by two sigma) places all bar one specimen of Beothukis (the holotype, oriented at $95^{\circ}$ ) within the C. procerus confidence interval-and indeed, within the $95 \%$ confidence intervals of all other southerly-oriented taxa. Thus, the Beothukis and C. procerus populations do not have significantly different orientations. It is possible of course that the Beothukis holotype belongs to a different species than the remainder of the population assigned by us to that taxon based on branching characters (McIlroy et al., 2020). However, recent work on the taxonomy of Beothukis, which demonstrates that the holotype is well within all other specimens with comparable morphology, and which were assigned by those authors to that taxon (Hawco et al., 2020) renders this unlikely. Indeed, an outlier of Primocandelabrum - whose morphology, and the orientations of the rest of the population, are entirely at odds with a reclined mode of life-is also oriented at $95^{\circ}$. Our orientation analyses of the Beothukis population demonstrates how the holotype orientation is an outlier and not representative of the population. Our results thus confirm an erect lifestyle for Beothukis (Wood et al., 2003; Laflamme and Narbonne 2008; Laflamme et al., 2012), contra McIlroy et al., 2020.

Charniodiscus procerus specimens-the taxon with the proportionally longest stem of any studied here (Laflamme et al., 2004)-are all oriented south, in a single cohort, with 1 

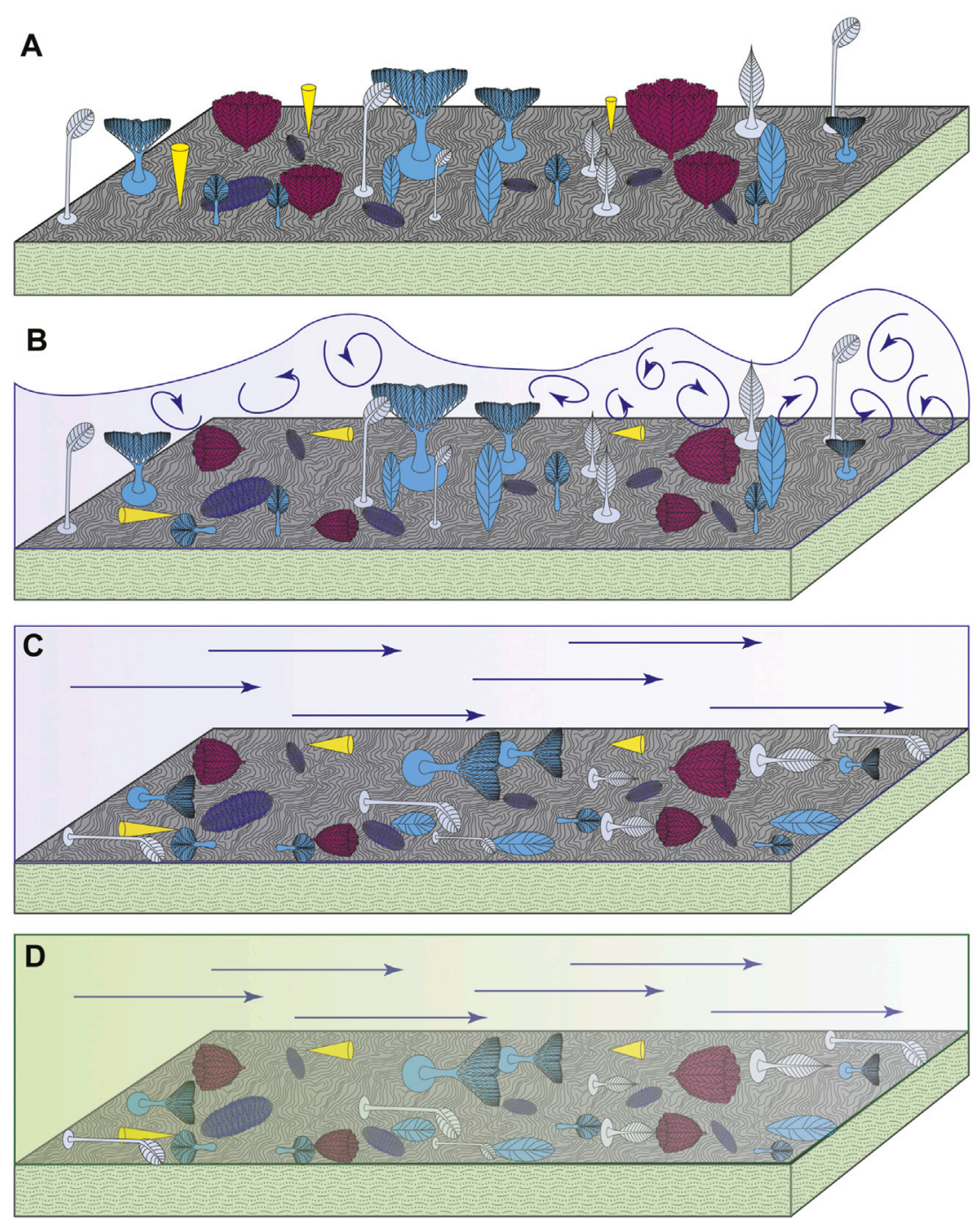

FIGURE 6 | Schematic illustrating the sequence of events that yield the preserved orientation distributions. (A) E surface community in life, with all fronds bar Fractofusus having an upright mode of life. (B) The dilute, turbid head of the gravity flow fells organisms with a high centre of gravity, including Thectardis and Bradgatia, producing a bimodal orientation distribution pattern. Note the orientation of the turbulent eddies (indicated by curled dark blue lines) relative to the direction of overall flow. (C) The laminar tail of the gravity flow fells all other upright fronds on the surface. Increased sediment concentrations within the tail of the gravity flow dampen turbulence, so the remaining fronds are felled in a solely laminar flow regime (indicated by straight dark blue lines). (D) Ash settles out of the flow, and smothers the community with the preserved distribution of orientations. Yellow = Thectardis; pink = Bradgatia; dark blue = Fractofusus; grey = Charniodiscus procerus and Charniodiscus spinosus; blue = upright fronds felled with a unimodal orientation (Beothukis, Plumeropriscum and Primocandelabrum).

outlier individual oriented antipodally (Supplementary Figure S3). All bar one specimen of Beothukis is oriented south, although notably with greater variance than the stemmed arboreomorphs (Figure 4). All Plumeropriscum specimens are oriented south, along with the majority of Primocandelabrum (Figure 4). Two Primocandelabrum specimens are oriented in a different orientation, away from the main direction (Figure 4, Supplementary Figure S3). In contrast, Bradgatia specimens are divided almost equally between north and south felling directions (Figure 4). These data would suggest that there is a correlation between proportional stem length and felling direction, and for the multifoliate taxa, there seems to be a strong correlation between presence of a stem and felling direction. Thectardis - with its narrow base and wide top-like Bradgatia, also shows a significant portion felled in the northern direction (Figure 4).

Together, our data suggest that those taxa with bases that are proportionally narrow compared to the widths of their tops (Thectardis and Bradgatia) show significantly different felling behaviours to those taxa that are more elongate and equal in shape, and that those taxa with the longest and thickest stems show the most consistent felling direction. Beothukis, for example, appears to show a sympodial central axis (Brasier et al., 2012; Hawco et al., 2020), and has the widest spread of any of the unifoliate and dominantly south-felled taxa. Equally, although Primocandelabrum has a sturdy stem, it has a 
proportionally wide top, and two specimens that are felled at a different angle from the main population. Charniodiscus spinosus has a much shorter stem than $C$. procerus, and also has a few specimens that are felled antipodally. The top-heavy morphology of Primocandelabrum, Bradgatia and Thectardis would presumably induce greater drag compared to the more streamlined unifoliate fronds, making them more susceptible to felling-and also potentially to adhesion to the matground-though the sturdy stems of Primocandelabrum helping to redress this susceptibility in all bar a few individual cases.

Random labelling analyses suggest that these differences are not an artifact of different flow regimes in different areas, indicating that differences in orientations between stemmed and stemless organisms may reflect genuine differences in the effect of flow on stemmed and stemless taxa. Fronds and stems behave differently in flow: at a flow velocity of $0 \mathrm{~ms}^{-1}$, both the frond and the stem will be fully upright, with no deflection, but as the flow velocity increases the tubular cross-section of the stem maximises the second moment of area, thus reducing the extent of bending under stress, and so this tubular morphology would serve to reduce the probability of failure via buckling (Wegst and Ashby 2007). Indeed, the high and positive epirelief of Charniodiscus procerus stems (Figure 2A) may indicate further biomechanical adaptation to flow conditions via wall thickening or changes in tissue rheology. Perhaps, because of this morphology the stem impeded felling of stemmed taxa within the enhanced velocities of the turbulent head of a turbidity flow, according with studies concerning the mechanical properties of stems, for example crinoids and aquatic plants (Baumiller and Ausich 1996; Ming-Chao and Chang-Feng 1996; Luhar and Nepf 2011).

Our interpretations are further supported by differential resolution of preservation between taxa. We observe the finest resolution of rangeomorph element preservation within Bradgatia (Figure 2B) and Beothukis (Figure 2A,C), whereas the primary branching units of Primocandelabrum and Plumeropriscum are rarely well-defined (Figure 2F,G). Though this may reflect a taphonomic signature, common membership within Rangeomorpha suggests similar modes of element construction, and instead we favour an interpretation comparable to that of Laflamme et al. (2004), wherein increasing volumes of sediment between the mat and the organism reduce preservation. This corroborates our model of comparatively rapid felling of the stemless Bradgatia and Beothukis (Thectardis does not possess rangeomorph branching, and thus cannot be considered here), whereas the stemmed Primocandelabrum and Plumeropriscum remained upright while small quantities of sediment were deposited out of the flow and onto the mat, precluding finescale preservation of the frondlets. Indeed, most Charniodiscus procerus specimens exhibit poorly-preserved fronds, consistent with our model-though note that arboreomorph tissue properties may differ from those of rangeomorphs, and thus may limit intercomparability.

These data support a two-phase model of felling (Figure 6), corresponding to the different flow regimes within a gravity flow. We infer that during the turbulent head of the flow, most fronds were buffeted by Kelvin-Helmholtz vortices. However, some easilyfelled taxa (Bradgatia and Thectardis) were felled by this turbulence, producing a bimodal distribution of felling orientations (Figures 4, 6). The transition to laminar flow within the body of the turbidity flow led to the felling of most remaining fronds, in a unimodal distribution (Figures 4, 6). In Charnwood Forest, we know that at least some fronds were capable of surviving small-scale disturbance events (Wilby et al., 2015). Wilby et al. focussed on the bimodal population structures of the unifoliate rangeomorph Charnia, but documented other, stemmed taxa that were also preserved with a bimodal population structure (Primocandelabrum, Hylaecullulus and Charniodiscus). Together with our data, this suggests that stemmed and elongate taxa showed greater survivability in high velocity flow. Height in the water column has previously been demonstrated to increase propagule dispersal, and doesn't appear to provide refuge from resource competition (Mitchell and Kenchington 2018). Our work suggests that stems may have had an additional function-lending greater resilience to felling in turbulent and high velocity flow regimes. These insights hint at potential environmental influences on the morphological composition of Ediacaran organisms.

\section{CONCLUSIONS}

We provide robust quantitative analyses of the orientation of populations of specimens from the Mistaken Point E surface. Our data support traditional palaeobiological models for the life habits of different organisms which lived in this community, with the majority of frondose organisms living upright in the water column while the spindle-shaped Fractofusus lived flat on the seafloor. Previous authors have suggested that current type and flow rate may impact community composition, but we demonstrate for the first time how the presence or absence of anatomical features impact survivability in different flow regimes. Specifically, we find that the presence of a stem (and potentially its proportional length) lends greater resilience to turbulent currents. Future work may find that such traits affect the presence and abundance of different morphologies under different environmental conditions, and potentially even the structuring of communities as they experience changing flow conditions.

\section{DATA AVAILABILITY STATEMENT}

The original contributions presented in the study are included in the article/Supplementary Material, further inquiries can be directed to the corresponding author.

\section{AUTHOR CONTRIBUTIONS}

PV conceived and designed the project. Analyses were performed PV and EM. PV, EM and CK contributed to data collection from 
photosquares and all authors (PV, CK, FD and EM) contributed to the writing up of the final manuscript.

\section{FUNDING}

This work has been supported by the Natural Environment Research Council Independent Research Fellowship NE/ S014756/1 to EGM and a Natural Environment Research Council grant NE/V010859/1 to FSD. FSD acknowledges support from the Royal Commission for the Exhibition of 1851 and Merton College, Oxford. CGK was supported by Leverhulme Trust (ECF-2018-542) and by the Isaac Newton Trust 18.08(H).

\section{REFERENCES}

Agostinelli, C., and Agostinelli, M. C. (2018). "CircStats Package," in Topics in Circular Statistics.

Baas, J. H., Best, J. L., Peakall, J., and Wang, M. (2009). A Phase Diagram for Turbulent, Transitional, and Laminar Clay Suspension Flows. J. Sediment. Res. 79, 162-183. doi:10.2110/jsr.2009.025

Baas, J. H., and Best, J. L. (2002). Turbulence Modulation in Clay-Rich SedimentLaden Flows and Some Implications for Sediment Deposition. J. Sediment. Res. 72, 336-340. doi:10.1306/120601720336

Bamforth, E. L., Narbonne, G. M., and Anderson, M. M. (2008). Growth and Ecology of a Multi-Branched Ediacaran Rangeomorph from the Mistaken Point Assemblage, Newfoundland. J. Paleontol. 82, 763-777. doi:10.1666/07-112.1

Bamforth, E. L., and Narbonne, G. M. (2009). New Ediacaran Rangeomorphs from Mistaken Point, Newfoundland, Canada. J. Paleontol. 83, 897-913. doi:10.1666/ 09-047.1

Baumiller, T. K., and Ausich, W. I. (1996). Crinoid Stalk Flexibility: Theoretical Predictions and Fossil Stalk Postures. Lethaia 29, 47-59. doi:10.1111/j.15023931.1996.tb01836.x

Benhadi-Marín, J. (2018). A Conceptual Framework to deal with Outliers in Ecology. Biodivers Conserv 27, 3295-3300. doi:10.1007/s10531-018-1602-2

Bobrovskiy, I., Hope, J. M., Ivantsov, A., Nettersheim, B. J., Hallmann, C., and Brocks, J. J. (2018). Ancient Steroids Establish the Ediacaran Fossil Dickinsonia as One of the Earliest Animals. Science 361, 1246-1249. doi:10.1126/ science.aat 7228

Boynton, H., and Ford, T. D. (1995). Ediacaran Fossils from the Precambrian (Charnian Supergroup) of Charnwood Forest, Leicestershire, England. Mercian Geologist 13, 165-182. Available at: http://www.emgs.org.uk/files/mercian_ vol13on/Mercian\%20Geologist\%20volume\%2013\%201992-1995/MG13_4_ 1995_165_Boynton\&Ford_Ediacaran\%20fossils\%20from\%20Charnian\%20of \%20Charnwood\%20Forest.pdf

Brasier, M. D., and Antcliffe, J. B. (2009). Evolutionary Relationships within the Avalonian Ediacara Biota: New Insights from Laser Analysis. J. Geol. Soc. 166, 363-384. doi:10.1144/0016-76492008-011

Brasier, M. D., Antcliffe, J. B., and Liu, A. G. (2012). The Architecture of Ediacaran Fronds. Palaeontology 55, 1105-1124. doi:10.1111/j.1475-4983.2012.01164.x

Budd, G. E., and Jensen, S. (2017). The Origin of the Animals and a 'Savannah' Hypothesis for Early Bilaterian Evolution. Biol. Rev. 92, 446-473. doi:10.1111/ brv.12239

Burzynski, G., and Narbonne, G. M. (2015). The Discs of Avalon: Relating Discoid Fossils to Frondose Organisms in the Ediacaran of Newfoundland, Canada. Palaeogeogr. Palaeoclimatol. Palaeoecol. 434, 34-45. doi:10.1016/ j.palaeo.2015.01.014

Cantero, M. I., Cantelli, A., Pirmez, C., Balachandar, S., Mohrig, D., Hickson, T. A., et al. (2012). Emplacement of Massive Turbidites Linked to Extinction of Turbulence in Turbidity Currents. Nat. Geosci 5, 42-45. doi:10.1038/ngeo1320

Cartigny, M. J. B., Eggenhuisen, J. T., Hansen, E. W. M., and Postma, G. (2013). Concentration-Dependent Flow Stratification in Experimental High-Density

\section{ACKNOWLEDGMENTS}

The Parks and Natural Areas Division (PNAD), Department of Environment and Conservation, Government of Newfoundland and Labrador, provided permits to conduct research within the Mistaken Point Ecological Reserve (MPER) in 2010, 2016 and 2017. Readers are advised that access to MPER is by scientific research permit only.

\section{SUPPLEMENTARY MATERIAL}

The Supplementary Material for this article can be found online at: https:/www.frontiersin.org/articles/10.3389/feart.2021.762824/ full\#supplementary-material

Turbidity Currents and Their Relevance to Turbidite Facies Models. J. Sediment. Res. 83, 1047-1065. doi:10.2110/jsr.2013.71

Clapham, M. E., and Narbonne, G. M. (2002). Ediacaran Epifaunal Tiering. Geology 30 (7), 627-630. doi:10.1130/0091-7613(2002)030\%3C0627:EET\% 3E2.0.CO;2

Clapham, M. E., Narbonne, G. M., Gehling, J. G., Greentree, C., and Anderson, M. M. (2004). Thectardis Avalonensis: A New Ediacaran Fossil from the Mistaken Point Biota, Newfoundland. J. Paleontol. 78, 1031-1036. doi:10.1017/ s0022336000043857

Clapham, M. E., Narbonne, G. M., and Gehling, J. G. (2003). Paleoecology of the Oldest Known Animal Communities: Ediacaran Assemblages at Mistaken Point, Newfoundland. Paleobiology 29, 527-544. doi:10.1666/00948373(2003)029<0527:potoka $>2.0 . c 0 ; 2$

Darroch, S. A. F., Smith, E. F., Laflamme, M., and Erwin, D. H. (2018). Ediacaran Extinction and Cambrian Explosion. Trends Ecol. Evol. 33, 653-663. doi:10.1016/j.tree.2018.06.003

Dececchi, T. A., Narbonne, G. M., Greentree, C., and Laflamme, M. (2017). Relating Ediacaran Fronds. Paleobiology 43, 171-180. doi:10.1017/pab.2016.54

Demko, T. (1995). in Proceedings of the Third Annual Fossils of Arizona Symposium, November 18, 1995. Editor M. S. Museum (American Traveler Press), 111.

Diggle, P., Zheng, P., and Durr, P. (2005). Nonparametric Estimation of Spatial Segregation in a Multivariate point Process: Bovine Tuberculosis in Cornwall, UK. J. R. Stat. Soc C 54, 645-658. doi:10.1111/j.14679876.2005.05373.x

Dunn, F. S., Liu, A. G., Grazhdankin, D. V., Vixseboxse, P., Flannery-Sutherland, J., Green, E., et al. (2021). The Developmental Biology of Charnia and the Eumetazoan Affinity of the Ediacaran Rangeomorphs. Sci. Adv. 7, eabe0291. doi:10.1126/sciadv.abe0291

Dunn, F. S., Liu, A. G., and Donoghue, P. C. J. (2018). Ediacaran Developmental Biology. Biol. Rev. 93, 914-932. doi:10.1111/brv.12379

Dunn, F. S., Wilby, P. R., Kenchington, C. G., Grazhdankin, D. V., Donoghue, P. C. J., and Liu, A. G. (2019). Anatomy of the Ediacaran rangeomorph Charnia Masoni. Pap. Palaeontol. 5, 157-176. doi:10.1002/spp2.1234

Dynowski, J. F., Nebelsick, J. H., Klein, A., and Roth-Nebelsick, A. (2016). Computational Fluid Dynamics Analysis of the Fossil Crinoid Encrinus liliiformis (Echinodermata: Crinoidea). PLOS ONE 11, e0156408. doi:10.1371/journal.pone.0156408

Fisher, R. V. (1983). Flow Transformations in Sediment Gravity Flows. Geol 11, 273-274. doi:10.1130/0091-7613(1983)11<273:ftisgf $>2.0$. co;2

Fitak, R. R., and Johnsen, S. (2017). Bringing the Analysis of Animal Orientation Data Full circle: Model-Based Approaches with Maximum Likelihood. J. Exp. Biol. 220, 3878-3882. doi:10.1242/jeb.167056

Flude, L. I., and Narbonne, G. M. (2008). Taphonomy and Ontogeny of a Multibranched Ediacaran Fossil: Bradgatia from the Avalon Peninsula of Newfoundland. Can. J. Earth Sci. 45, 1095-1109. doi:10.1139/ e08-057

Ford, T. D. (1958). Pre-Cambrian Fossils from Charnwood Forest. Proc. Yorks. Geol. Soc. 31, 211-217. doi:10.1144/pygs.31.3.211 
Fraley, C., and Raftery, A. E. (2017). MCLUST Version 3 for R: Normal Mixture Modeling and Model-Based Clustering*. Washington: MCLUST, 57.

Gehling, J. G., and Narbonne, G. M. (2007). Spindle-shaped Ediacara Fossils from the Mistaken Point Assemblage, Avalon Zone, Newfoundland. Can. J. Earth Sci. 44, 367-387. doi:10.1139/e07-003

Ghisalberti, M., Gold, D. A., Laflamme, M., Clapham, M. E., Narbonne, G. M., Summons, R. E., et al. (2014). Canopy Flow Analysis Reveals the Advantage of Size in the Oldest Communities of Multicellular Eukaryotes. Curr. Biol. 24, 305-309. doi:10.1016/j.cub.2013.12.017

Hallworth, M. A., Phillips, J. C., Huppert, H. E., and Sparks, R. S. J. (1993). Entrainment in Turbulent Gravity Currents. Nature 362, 829-831. doi:10.1038/ $362829 \mathrm{a} 0$

Haughton, P., Davis, C., McCaffrey, W., and Barker, S. (2009). Hybrid Sediment Gravity Flow Deposits - Classification, Origin and Significance. Mar. Pet. Geology. 26, 1900-1918. doi:10.1016/j.marpetgeo.2009.02.012

Hawco, J. B., Kenchington, C. G., Taylor, R. S., and McIlroy, D. (2020). A Multivariate Statistical Analysis of the Ediacaran Rangeomorph Taxa Beothukis and Culmofrons. PALAIOS 35, 495-511. doi:10.2110/palo.2020.049

Hofmann, H. J., O’Brien, S. J., and King, A. F. (2008). Ediacaran Biota on Bonavista Peninsula, Newfoundland, Canada. J. Paleontol. 82, 1-36. doi:10.1666/06-087.1

Hoyal Cuthill, J. F., and Conway Morris, S. (2014). Fractal Branching Organizations of Ediacaran Rangeomorph Fronds Reveal a Lost Proterozoic Body Plan. Proc. Natl. Acad. Sci. 111, 13122-13126. doi:10.1073/pnas.1408542111

Hoyal Cuthill, J. F., and Han, J. (2018). Cambrian Petalonamid Stromatoveris Phylogenetically Links Ediacaran Biota to Later Animals. Palaeontology 61, 813-823. doi:10.1111/pala.12393

Ichaso, A. A., Dalrymple, R. W., and Narbonne, G. M. (2007). Paleoenvironmental and basin Analysis of the Late Neoproterozoic (Ediacaran) Upper Conception and St. John's Groups, West Conception Bay, Newfoundland. Can. J. Earth Sci. 44, 25-41. doi:10.1139/e06-098

Illian, J., Penttinen, P. A., Stoyan, D. H., and Stoyan, D. D. (2008). Statistical Analysis and Modelling of Spatial Point Patterns. Wiley, 560.

Jones, M. L., and Dennison, J. M. (1970). Oriented Fossils as Paleocurrent Indicators in Paleozoic Lutites of Southern Appalachians. J. Sediment. Res. 40, 642-649. doi:10.1306/74d71ff5-2b21-11d7-8648000102c1865d

Kenchington, C. G., Harris, S. J., Vixseboxse, P. B., Pickup, C., and Wilby, P. R. (2018). The Ediacaran Fossils of Charnwood Forest: Shining New Light on a Major Biological Revolution. Proc. Geologists' Assoc. 129, 264-277. doi:10.1016/ j.pgeola.2018.02.006

Kenchington, C. G., and Wilby, P. R. (2017). Rangeomorph Classification Schemes and Intra-specific Variation: Are All Characters Created Equal? Geol. Soc. Lond. Spec. Publications 448, 221-250. doi:10.1144/sp448.19

Kiipli, T., Kiipli, E., Kallaste, T., Hints, R., Somelar, P., and Kirsimäe, K. (2007). Altered Volcanic Ash as an Indicator of marine Environment, Reflecting Ph and Sedimentation Rate - Example from the Ordovician Kinnekulle Bed of Baltoscandia. Clays Clay Miner. 55, 177-188. doi:10.1346/ ccmn.2007.0550207

Koehl, M. A. R. (1977a). Effects of Sea Anemones on the Flow Forces They Encounter. J. Exp. Biol. 69, 87-105. doi:10.1242/jeb.69.1.87

Koehl, M. A. R. (1977b). Mechanical Organization of Cantileverlike Sessile Organisms: Sea Anemones. J. Exp. Biol. 69, 127-142. doi:10.1242/jeb.69.1.127

Laflamme, M., Darroch, S. A. F., Tweedt, S. M., Peterson, K. J., and Erwin, D. H. (2013). The End of the Ediacara Biota: Extinction, Biotic Replacement, or Cheshire Cat? Gondwana Res. 23, 558-573. doi:10.1016/j.gr.2012.11.004

Laflamme, M., Flude, L. I., and Narbonne, G. M. (2012). Ecological Tiering and the Evolution of a Stem: the Oldest Stemmed Frond from the Ediacaran of Newfoundland, Canada. J. Paleontol. 86, 193-200. doi:10.1666/11-044.1

Laflamme, M., Gehling, J. G., and Droser, M. L. (2018). Deconstructing an Ediacaran Frond: Three-Dimensional Preservation of Arborea from Ediacara, South Australia. J. Paleontol. 92, 323-335. doi:10.1017/jpa.2017.128

Laflamme, M., Narbonne, G. M., and Anderson, M. M. (2004). Morphometric Analysis of the Ediacaran Frond Charniodiscus from the Mistaken Point Formation, Newfoundland. J. Paleontol. 78, 827-837. doi:10.1666/00223360(2004)078<0827:maotef $>2.0 . c 0 ; 2$

Laflamme, M., and Narbonne, G. M. (2008). Ediacaran Fronds. Palaeogeogr. Palaeoclimatol. Palaeoecol. 258, 162-179. doi:10.1016/j.palaeo.2007.05.020
Laflamme, M., Xiao, S., and Kowalewski, M. (2009). Osmotrophy in Modular Ediacara Organisms. Proc. Natl. Acad. Sci. 106, 14438-14443. doi:10.1073/ pnas. 0904836106

Landler, L., Ruxton, G. D., and Malkemper, E. P. (2019). The Hermans-Rasson Test as a Powerful Alternative to the Rayleigh Test for Circular Statistics in Biology. BMC Ecol. 19, 30. doi:10.1186/s12898-019-0246-8

Liu, A. G. (2016). Framboidal Pyrite Shroud Confirms the 'Death Mask' Model for Mouldic Preservation of Ediacaran Soft-Bodied Organisms. PALAIOS 31 (5), 259-274. doi:10.2110/palo.2015.095

Liu, A. G., Kenchington, C. G., and Mitchell, E. G. (2015). Remarkable Insights into the Paleoecology of the Avalonian Ediacaran Macrobiota. Gondwana Res. 27, 1355-1380. doi:10.1016/j.gr.2014.11.002

Liu, A. G., Mcilroy, D., Antcliffe, J. B., and Brasier, M. D. (2011). Effaced Preservation in the Ediacara Biota and its Implications for the Early Macrofossil Record. Palaeontology 54, 607-630. doi:10.1111/j.14754983.2010.01024.x

Liu, X., and Jiang, Y. (2014). Direct Numerical Simulations of Boundary Condition Effects on the Propagation of Density Current in wall-bounded and Open Channels. Environ. Fluid Mech. 14, 387-407. doi:10.1007/s10652-013-9283-6

Luhar, M., and Nepf, H. M. (2011). Flow-induced Reconfiguration of Buoyant and Flexible Aquatic Vegetation. Limnol. Oceanogr. 56, 2003-2017. doi:10.4319/lo.2011.56.6.2003

Mason, S. J., and Narbonne, G. M. (2016). Two New Ediacaran Small Fronds from Mistaken Point, Newfoundland. J. Paleontol. 90, 183-194. doi:10.1017/ jpa.2016.14

Matthews, J. J., Liu, A. G., Yang, C., McIlroy, D., Levell, B., and Condon, D. J. (2021). A Chronostratigraphic Framework for the Rise of the Ediacaran Macrobiota: New Constraints from Mistaken Point Ecological Reserve, Newfoundland. GSA Bull. 133:612-624, doi:10.1130/b35646.1

McIlroy, D., Hawco, J., McKean, C., Nicholls, R., Pasinetti, G., and Taylor, R. (2020). Palaeobiology of the Reclining Rangeomorph Beothukis from the Ediacaran Mistaken Point Formation of southeastern Newfoundland. Geol. Mag., 1-15. doi:10.1017/s0016756820000941

Ming-Chao, L., and Chang-Feng, D. (1996). Drag, Morphology and Mechanical Properties of Three Species of Octocorals. J. Exp. Mar. Biol. Ecol. 1 (2), 13-22.

Mitchell, E. G., Bobkov, N., Bykova, N., Dhungana, A., Kolesnikov, A. V., Hogarth, I. R. P., et al. (2020). The Influence of Environmental Setting on the Community Ecology of Ediacaran Organisms. Interf. Focus 10, 20190109. doi:10.1098/ rsfs.2019.0109

Mitchell, E. G., and Butterfield, N. J. (2018). Spatial Analyses of Ediacaran Communities at Mistaken Point. Paleobiology 44, 40-57. doi:10.1017/ pab.2017.35

Mitchell, E. G., Harris, S., Kenchington, C. G., Vixseboxse, P., Roberts, L., Clark, C., et al. (2019). The Importance of Neutral over Niche Processes in Structuring Ediacaran Early Animal Communities. Ecol. Lett. 22, 2028-2038. doi:10.1111/ele.13383

Mitchell, E. G., and Harris, S. (2020). Mortality, Population and Community Dynamics of the Glass Sponge Dominated Community "The Forest of the Weird" from the Ridge Seamount, Johnston Atoll, Pacific Ocean. Front. Mar. Sci. 7. doi: $10.3389 /$ fmars. 2020.565171

Mitchell, E. G., Kenchington, C. G., Harris, S., and Wilby, P. R. (2018). Revealing Rangeomorph Species Characters Using Spatial Analyses. Can. J. Earth Sci. 55, 1262-1270. doi:10.1139/cjes-2018-0034

Mitchell, E. G., Kenchington, C. G., Liu, A. G., Matthews, J. J., and Butterfield, N. J. (2015). Reconstructing the Reproductive Mode of an Ediacaran MacroOrganism. Nature 524, 343-346. doi:10.1038/nature14646

Mitchell, E. G., and Kenchington, C. G. (2018). The Utility of Height for the Ediacaran Organisms of Mistaken Point. Nat. Ecol. Evol. 2, 1218-1222. doi:10.1038/s41559-018-0591-6

Narbonne, G. M., and Gehling, J. G. (2003). Life after Snowball: The Oldest Complex Ediacaran Fossils. Geol 31, 27-30. doi:10.1130/0091-7613(2003) $031<0027$ :lastoc $>2.0$. co 2

Narbonne, G. M. (2004). Modular Construction of Early Ediacaran Complex Life Forms. Science 305, 1141-1144. doi:10.1126/science.1099727

Narbonne, G. M. (2005). The Ediacara Biota: Neoproterozoic Origin of Animals and Their Ecosystems. Annu. Rev. Earth Planet. Sci. 33, 421-442. doi:10.1146/ annurev.earth.33.092203.122519

Noble, S. R., Condon, D. J., Carney, J. N., Wilby, P. R., Pharaoh, T. C., and Ford, T. D. (2015). U-pb Geochronology and Global Context of the Charnian 
Supergroup, UK: Constraints on the Age of Key Ediacaran Fossil Assemblages. Geol. Soc. America Bull. 127, 250-265. doi:10.1130/b31013.1

Rao, J. S. (1976). Some Tests Based on Arc-Lengths for the Circle. Sankhyā: Indian J. Stat. $38,329-338$.

Schnute, J. T., and Groot, K. (1992). Statistical Analysis of Animal Orientation Data. Anim. Behav. 43, 15-33. doi:10.1016/s0003-3472(05)80068-5

Seilacher, A. (1992). Vendobionta and Psammocorallia: Lost Constructions of Precambrian Evolution. J. Geol. Soc. 149, 607-613. doi:10.1144/ gsjgs.149.4.0607

Shen, B., Dong, L., Xiao, S., and Kowalewski, M. (2008). The Avalon Explosion: Evolution of Ediacara Morphospace. Science 319, 81-84. doi:10.1126/ science. 1150279

Shringarpure, M., Cantero, M. I., and Balachandar, S. (2012). Dynamics of Complete Turbulence Suppression in Turbidity Currents Driven by Monodisperse Suspensions of Sediment. J. Fluid Mech. 712, 384-417. doi:10.1017/jfm.2012.427

Smith, P. L. (1980). Determining the In Situ Orientation of Fossil Bilateral Symmetry Planes during Paleocurrent Analysis. J. Paleontol. 54, 1121-1123. Available at: https://www.jstor.org/stable/1304378

Sparks, R. S. J., and Wilson, C. J. N. (1983). Flow-head Deposits in Ash Turbidites. Geol 11, 348-351. doi:10.1130/0091-7613(1983)11<348: fdiat $>2.0 . \operatorname{co} ; 2$

Sperling, E. A., Peterson, K. J., and Laflamme, M. (2011). Rangeomorphs, Thectardis (Porifera?) and Dissolved Organic Carbon in the Ediacaran Oceans. Geobiology 9, 24-33. doi:10.1111/j.1472-4669.2010.00259.x

Talling, P. J., Masson, D. G., Sumner, E. J., and Malgesini, G. (2012). Subaqueous Sediment Density Flows: Depositional Processes and deposit Types. Sedimentology 59, 1937-2003. doi:10.1111/j.1365-3091.2012.01353.x

Toots, H. (1965). Orientation and Distribution of Fossils as Environmental Indicators. Springs: Sedimentation of Late Cretaceous and Tertiary Outcrops, 219-229.

Waggoner, B. (2003). The Ediacaran Biotas in Space and Time. Integr. Comp. Biol. 43, 104-113. doi:10.1093/icb/43.1.104

Wegst, U. G. K., and Ashby, M. F. (2007). The Structural Efficiency of Orthotropic Stalks, Stems and Tubes. J. Mater. Sci. 42, 9005-9014. doi:10.1007/s10853-0071936-8

Wiegand, T., and Moloney, K. A. (2013). Handbook of Spatial Point-Pattern Analysis in Ecology. Boca Raton, FL: CRC Press.
Wilby, P. R., Carney, J. N., and Howe, M. P. A. (2011). A Rich Ediacaran Assemblage from Eastern Avalonia: Evidence of Early Widespread Diversity in the Deep Ocean. Geology 39, 655-658. doi:10.1130/g31890.1

Wilby, P. R., Kenchington, C. G., and Wilby, R. L. (2015). Role of Low Intensity Environmental Disturbance in Structuring the Earliest (Ediacaran) Macrobenthic Tiered Communities. Palaeogeogr. Palaeoclimatol. Palaeoecol. 434, 14-27. doi:10.1016/j.palaeo.2015.03.033

Wood, D. A., Dalrymple, R. W., Narbonne, G. M., Gehling, J. G., and Clapham, M. E. (2003). Paleoenvironmental Analysis of the Late Neoproterozoic Mistaken Point and Trepassey Formations, southeastern Newfoundland. Can. J. Earth Sci. 40, 1375-1391. doi:10.1139/e03-048

Wood, R., Liu, A. G., Bowyer, F., Wilby, P. R., Dunn, F. S., Kenchington, C. G., et al. (2019). Integrated Records of Environmental Change and Evolution challenge the Cambrian Explosion. Nat. Ecol. Evol. 3, 528-538. doi:10.1038/s41559-019-0821-6

Xiao, S., and Laflamme, M. (2009). On the Eve of Animal Radiation: Phylogeny, Ecology and Evolution of the Ediacara Biota. Trends Ecol. Evol. 24, 31-40. doi:10.1016/j.tree.2008.07.015

Conflict of Interest: The authors declare that the research was conducted in the absence of any commercial or financial relationships that could be construed as a potential conflict of interest.

The handling Editor declared a past co-authorship with one of the authors (EM).

Publisher's Note: All claims expressed in this article are solely those of the authors and do not necessarily represent those of their affiliated organizations, or those of the publisher, the editors and the reviewers. Any product that may be evaluated in this article, or claim that may be made by its manufacturer, is not guaranteed or endorsed by the publisher.

Copyright $\odot 2021$ Vixseboxse, Kenchington, Dunn and Mitchell. This is an openaccess article distributed under the terms of the Creative Commons Attribution License (CC BY). The use, distribution or reproduction in other forums is permitted, provided the original author(s) and the copyright owner(s) are credited and that the original publication in this journal is cited, in accordance with accepted academic practice. No use, distribution or reproduction is permitted which does not comply with these terms. 